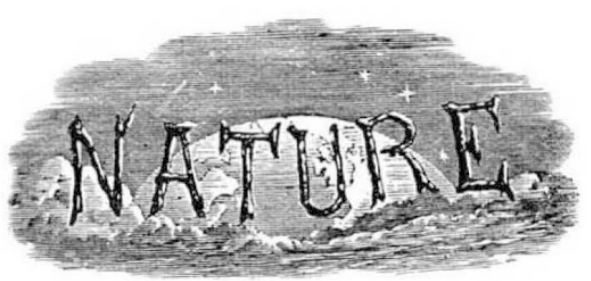

SATURDAY, FEBRUARY 27, 1932

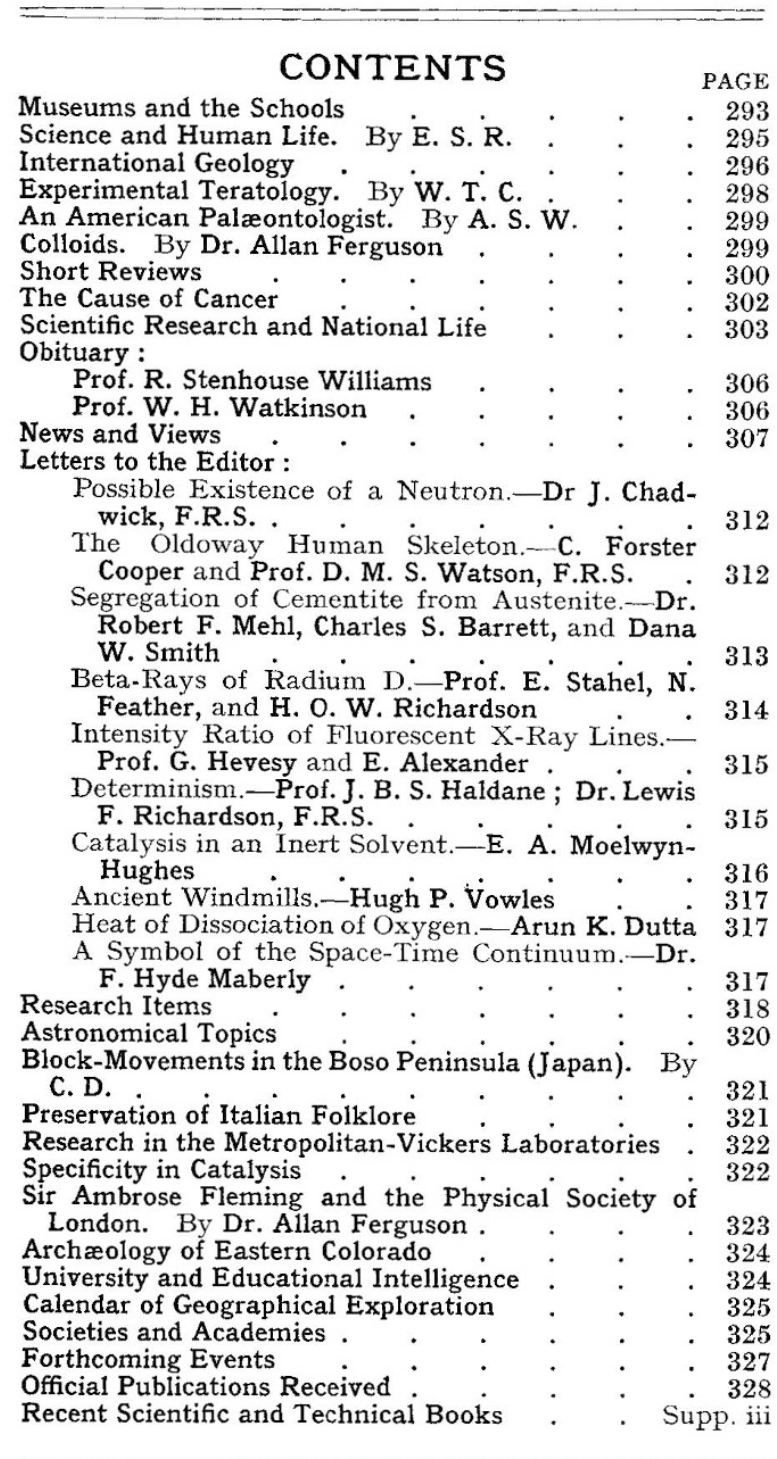

Editorial and Publishing Offices:

MACMILLAN \& CO., LTD.

ST. MARTIN'S STREET, LONDON, W.C. 2

Editorial communications should be addressed to the Editor Advertisements and business letters to the Publishers

Telephone Number: GERRARD 8830

Telegraphic Address: PHUSIS, WESTRAND, LONDON No. 3252, VoL. 129]

\section{Museums and the Schools*}

A SMALL pamphlet recently prepared by the A Board of Education is of greater importance than its appearance might suggest, in that it brings the whole weight of the Board to bear in favour of the more extended use of museum materials by the various educational establishments of England. The pamphlet begins with a short historical summary, leading to a condensed survey of the present position; it then illustrates its aim by examples from the United States, Germany, Scandinavia, England, and Wales; and finally it indicates methods of co-operation already followed in isolated places as worthy of general adoption. Since no one seriously interested in either museums or practical teaching need grudge the small sum asked or the short time required to buy and study the booklet, it would be inadvisable to prevent him by any more detailed abstract of its contents. The publication does, however, suggest comment on a few of the broader matters involved.

The general question is the use of actual concrete objects in teaching as opposed to mere words. This has of late years been termed 'visual instruction'obviously an inexact phrase, for 'visual' applies equally to book learning but does not apply to the handling of objects by the blind, which is merely an extreme case of the handling recommended for all pupils by the pamphlet. The use of this concrete method has undoubtedly spread with increasing rapidity during the past half-century, both up from the kindergarten and down from the laboratory. As regards the extremes of the educational scale, not much requires to be said: they have recognised their needs and have provided for them. It is for the intermediate region that missionary work and practical assistance are now desired.

The museums formed by various departments of universities, by art schools, and by technical and commercial colleges serve adequately the wants of those special students for whom they are designed. It is, however, suggested that the material in those semi-private museums might sometimes be made more accessible to the public, and that there might be more co-operation between those institutions and the public museum of the locality At present it is the schools of art, craft, and trade that make most use of the public museums; the curators welcome visits from such students, and occasionally receive in turn some help in their installations from

* Board of Education. Educational Pamphlets No. 87: Memorandum on the Possibility of increased Co-operation between Public Museums and Public Educational Institutions. Pp. 45. (London: H.M. Stationery Office, 1931.) $9 d$. net. 
the art people. With scientific material the case appears to be different. Curators would no doubt be grateful for more of such help in the determination and classification of their specimens as university professors could render; but when there is a question of a quid pro quo it is found that methods of exhibition well adapted to the serious student are not always such as appeal to the public, while it is dangerous to admit pupils-and, sometimes, even professors- to the run of the cases and the free handling of material. With good will and a sympathetic understanding of each other's difficulties, much more could be done to mutual advantage, but in general the best plan is to have distinct collections for distinct purposes.

It is, however, the utilisation of museum material by the secondary and elementary schools that demands chief consideration. It is assumed that almost every school subject, even the teaching of a foreign language (living or dead), may be enlivened by the introduction of illustrative objects. The first question, then, is the provision of such objects. The richest and, in many cases, the only possible source of them is a well-stocked museum; and thus the problem becomes the best means of bringing the class and the collections into profitable contact. Either the school may send its pupils to the museum, or the museum may send specimens to the school. There is much to be said for and against both methods.

Consider, first, visits to a museum. It is plainly the main duty of a curator to place and keep in good order the specimens in his charge. So far as their educational use is concerned, it is his business to display attractive series that shall by arrangement or labelling tell their own story. One consequence of this is that the lesson of the specimens is most easily apprehended in a museum, where also each exhibit is, or should be, seen in its due relation to allied material. The pupils may at the same time be stimulated by the visit, and may be impressed by the surrounding neatness and order. On the other hand, it is maintained by some that the unfamiliar surroundings are distracting, and that the multiplicity of objects hinders concentration. Some museums, therefore, remove objects to a room set aside for teaching, and this enables the specimens to be handled, but only if they are duplicates provided for the purpose. By this compromise the pupils lose some advantages of a museum visit, while the curator and his collections are wrested from the primary purpose of the ordinary museum. The real objection, however, lies in the difficulty of bringing the classes, especially those from a distance, to the museum, and in the impossibility of each pupil coming to the museum often enough for the visit to take its desired place as a normal part of the curriculum.

We seem, then, to be thrown back on the other method, that of circulating small collections and specially designed exhibits to the schools. Started in Great Britain half a century ago, the method has received remarkable extension in the United States. If it has not grown in Britain in like degree, that is largely due to the lack of interest shown by education authorities. The Museums Association has lately sought to arouse them to a sense of its value, and the present benediction of the Board will doubtless help it forward. Admirable work is being done by several museums on these lines, and success is found to follow expenditure of thought rather than of money. But here again, if every school is to have a supply of material available at the right moment for the appropriate lessons, the number of circulating collections must be multiplied a hundred-fold. At present the collections serve as occasional stimuli, of great value, but far from satisfying the everyday demand. This method, moreover, makes a still greater call on the time of the museum staff, and usually necessitates the acquisition of fresh specimens for the particular purpose. To obviate some of its disadvantages, the Commercial Museum of Philadelphia has replaced circulating loans by gifts of large numbers of identical cases.

Thus we are led to a third method, the formation of school museums. There are many school museums, some excellent, several disreputable, but few on the lines required. What is needed is a collection formed in each school with definite reference to the curriculum. In the establishment of such a collection the pupils themselves should help ; guidance and some material can be obtained from the regional museum, and there are other sources from which appropriate specimens can be drawn, but, above all, every teacher should make use of it.

The last remark reminds us that, whatever method be adopted, the immediate task is to teach the teachers. Teaching is their business; it is not the curator's. The use of illustrative objects is more and more being inculcated in the training colleges, and to those who are thus trained the curator can explain the material he sends out and can suggest its use.

To sum up: the scheme that seems to be most practicable and promising the best results is a combination of all three methods:-The museum of

No. 3252, VoL. 129] 
the school, in which the school should take a pride, and which should be used to the full in class teaching as well as for spare-time hobbies: circulating loans to illustrate some particular, temporary subject, in supplement to the school collections: finally, as a reward and additional stimulus, a visit (if possible once a term) to the regional museum; this should be prepared for and should be under trained guidance. It will be long before such a scheme can be in working order, but it is the goal we would set before our educational museum enthusiasts. Meanwhile there are many things that can be done, on which space forbids us to dilate here. Some of them will be found in the excellent pamphlet that is our text.

\section{Science and Human Life}

(1) World Chaos: the Responsibility of Science. By William McDougall. Pp. vi +119 . (London : Kegan Paul and Co., Ltd., 1931.) 3s. 6d. net.

(2) The Scientific Outlook. By Bertrand Russell. Pp. 285. (London: George Allen and Unwin, Ltd., 1931.) $7 s .6 d$. net.

(3) What Dare I Think? The Challenge of Modern Science to Human Action and Belief, including the Henry La Barre Jayne Foundation Lectures (Philadelphia) for 1931. By Julian Huxley. Pp. ix +270 . (London: Chatto and Windus, 1931.) $7 s .6 d$. net.

TN these three books a psychologist, a mathe1 matical philosopher, and a biologist discuss the relation of science to human life. It is common ground that the application of scientific method has conferred enormous material benefits upon mankind--Prof. Huxley's account of the triumphs of applied biology is particularly well done-but in all three writers one discerns a feeling of uneasiness lest science become too powerful and affect prejudicially the harmonious development of man's mind and character.

(1) Prof. McDougall roundly asserts that the physical sciences are mainly responsible for the present world chaos, for they " have produced a complexity of our civilization which far outruns our present understanding and power of control". $\mathrm{He}$ would seek a remedy in more science, but in science of a different kind: in a thorough study of social and economic problems from a definitely psychological point of view. This point of view would be completely different from that of the physical sciences-McDougall entirely rejects the mechanistic treatment of life and mind as inadequate, and substitutes his own conative or hormic conception. His book is vigorously written, and his remarks on the present world crisis are extremely apt and timely.

(2) Mr. Bertrand Russell has much more faith in the value of mechanistic methods in biology and psychology, and in effect denies that any other method is scientific. His psychological gods appear to be Freud and Pavlov. We venture to think that he has been over-impressed by the claims of mechanistic biologists, and that with greater knowledge would come a less dogmatic attitude. His book is an interesting one, and deals in a skilful way, and not without a certain dry humour, with the principles of scientific method. Chapters on scientific metaphysics and science and religion give him an excellent opportunity, of which he takes full advantage, to criticise Jeans and Eddington in their excursions into philosophy.

The most significant part of the book, in our opinion, is the short last chapter on science and values. It follows a vivid presentation of what the world State of the future might be like if it were organised on purely scientific lines : a picture which, Mr. Russell agrees, is in some aspects nightmarish and depressing. Already in his introduction Mr. Russell had pointed out that if " a scientific civilization is to be a good civilization it is necessary that increase in knowledge should be accompanied by increase in wisdom ", meaning by wisdom a right conception of the ends of life. Science by itself can give no guidance as to values or ends. A society deliberately constructed on scientific principles, without regard to values, might then be a very bad society.

If we read Mr. Russell aright, he views the possibility of a scientific world State with grave misgiving, and this because the power over Nature which science gives may come to be regarded as an end in itself. The love of knowledge, from which science springs, has, Mr. Russell tells us, a twofold origin. "We may seek knowledge of an object because we love the object or because we wish to have power over it. The former impulse leads to the kind of knowledge that is contemplative, the latter to the kind that is practical. In the development of science the power impulse has increasingly prevailed over the love impulse" ( $p$. $270)$. "The scientific society of the future as we have been imagining it is one in which the power impulse has completely overwhelmed the impulse of love, and this is the psychological source of the cruelties which it is in danger of exhibiting " ( $p$. 273). Power cannot legitimately be regarded as one of the ends of life, but merely as a means to

No. 3252, VoL. 129] 